Published in final edited form as:

Nat Rev Gastroenterol Hepatol. 2009 July ; 6(7): 412-422. doi:10.1038/nrgastro.2009.89.

\title{
Pancreatic cancer: molecular pathogenesis and new therapeutic targets
}

\author{
Han H. Wong and \\ Centre for Molecular Oncology and Imaging, Barts and The London School of Medicine and \\ Dentistry, Queen Mary University of London, London, UK. \\ Nicholas R. Lemoine \\ Institute of Cancer, Barts and The London School of Medicine and Dentistry, Queen Mary \\ University of London, London, UK.
}

\begin{abstract}
Patients with pancreatic cancer normally present with advanced disease that is lethal and notoriously difficult to treat. Survival has not improved dramatically, despite routine use of chemotherapy and radiotherapy; this situation signifies an urgent need for novel therapeutic approaches. Over the past decade, a large number of studies that aimed to target the molecular abnormalities implicated in pancreatic tumor growth, invasion, metastasis, angiogenesis and resistance to apoptosis have been published. This research is of particular importance, as recent data suggest that a large number of genetic alterations affect only a few major signaling pathways and processes involved in pancreatic tumorigenesis. Although laboratory results of targeted therapies have been impressive, until now only erlotinib, an epidermal growth-factor receptor tyrosine kinase inhibitor, has demonstrated modest survival benefit in combination with gemcitabine in a phase III clinical trial. Whilst the failures of targeted therapies in the clinical setting are discouraging, lessons have been learnt and new therapeutic targets that hold promise for the future management of the disease are continuously emerging. This Review describes some of the important developments and targeted agents for pancreatic cancer that have been tested in clinical trials.
\end{abstract}

\section{Introduction}

Pancreatic cancer remains an important health problem. Known risk factors for the disease include cigarette smoking, chronic and hereditary pancreatitis, late-onset diabetes mellitus and familial cancer syndromes. Pancreatic cancer is one of the most difficult conditions to treat, although it only accounts for 3\% of all cancers; 5 -year survival is about $5 \%$ in patients with the disease and this figure has remained relatively unchanged over the past 25 years. 1 The majority of patients present with locally advanced or metastatic disease, and such individuals have a grim median survival of 6-10 months, and 3-6 months, respectively.2 Although $10-15 \%$ of patients have potentially resectable tumors, many experience recurrence of disease following surgery. Gemcitabine is the standard chemotherapeutic drug for patients with advanced pancreatic cancer after a phase III trial in 1997 demonstrated a modest survival advantage of this agent over 5-fluorouracil (median survival 5.65 months versus 4.41 months, respectively $P=0.0025$ ), and improved alleviation of disease-related symptoms. 3 Given the limited effect of conventional therapies, however, a desperate need

Correspondence: N. R. Lemoine, Institute of Cancer, Barts and The London School of Medicine and Dentistry, Queen Mary University of London, Charterhouse Square, London EC1M 6BQ, UK n.r.lemoine@qmul.ac.uk.

Competing interests The authors declare no competing interests. 
for improved diagnostic and treatment modalities remains. Considerable resources have been channeled to the development of novel therapies that target the molecular aberrations of the disease (Table 1). These targeted therapies are designed to disable the cellular pathways that are essential for cancer to survive. Targeted therapies could also be used in a multimodal treatment regimen in combination with standard radiotherapy and chemotherapy to improve outcomes and overcome drug resistance. In 2008, detailed, global, genomic analyses found that a large number of genetic alterations (an average of 63) affect only a core set of 12 signaling pathways and processes that are each genetically altered in $67-100 \%$ of cases of pancreatic cancer. 4 These data suggest that treatments for pancreatic cancer should target these complex and overlapping signaling pathways, rather than just the products of a single gene (Figure 1). This Review describes some of the important developments in therapies for pancreatic cancer that have been tested both in the laboratory and, most importantly, in subsequent clinical trials.

\section{Targeted therapies in clinical trials}

\section{Signal-transduction pathways}

The Ras Pathway-KRAS is a member of the Ras family of genes, which encode membrane-bound GTP-binding proteins. When activated by signaling partners, such as the epidermal growth factor receptor (EGFR), Ras proteins release GDP in exchange for GTP, which converts the Ras protein to the 'on' state and activates downstream signaling events, such as the Raf, MAP2K, MAPK and the PI3K-Akt cascades (Figure 2). These events are usually short-lived by virtue of the intrinsic GTPase activity of Ras proteins, which switches these proteins' effects 'off'. Mutations of $K R A S$, mostly at codon 12 but also sometimes at codons 13 and 61, are exceptionally frequent in patients with pancreatic cancer.5 Mutations in $K R A S$ result in impaired GTPase function, which causes KRas to be locked in the GTPbound 'on' state. This malfunction triggers a variety of cellular processes, including transcription, translation, cell-cycle progression, enhanced cell survival and motility. Oncogenic $K R A S$ is involved in the initiation or early phase of pancreatic tumorigenesis.

A peptide vaccine that aims to stimulate immunity against cancer cells with mutant Ras proteins has been tested as an adjuvant treatment in patients with pancreatic cancer.6 An extension to this research investigated the effects of combination therapy with mutant Ras peptide plus granulocyte-macrophage colony-stimulating factor7 or interleukin 2.8 Outcomes seemed to be favorable in these phase I-II trials, albeit only in individuals who mounted an immune response (about half of the patients).

For Ras to function, it must undergo post-translational modification so that it can attach to the cell membrane. One essential step involves the addition of a 15-carbon isoprenoid chain, mediated by farnesyltransferase. The therapeutic use of tipifarnib, a farnesyltransferase inhibitor (FTI), in combination with gemcitabine was disappointing in a phase III trial (Table 2).9 This finding could be partly explained by the fact that KRas can be alternatively prenylated by the addition of a 20-carbon isoprenoid moiety mediated by the enzyme geranylgeranyltransferase. Moreover, FTIs work largely by inhibition of the cell cycle, but gemcitabine needs cell-cycle progression to be effective. To this end, a dual inhibitor of farnesyltransferase and geranylgeranyltransferase (L-778,123) was tested in a phase I trial in combination with radiotherapy for locally advanced pancreatic cancer.10 Inhibition of farnesylation and sensitivity to radiotherapy was demonstrated in a patient-derived cell line. Further development of this drug was, nevertheless, halted owing to adverse cardiac effects. Other compounds that are in early phases of clinical testing after yielding promising laboratory results include romidepsin, a histone deacetylase inhibitor that inhibits Rasmediated signal transduction and thus causes cell-cycle arrest,11 and farnesylthiosalicylic acid (salirasib), which disrupts Ras from its membrane-binding site. 12 These compounds 
seem to have clinical activity in combination with gemcitabine and further studies are warranted.

Other strategies that target the Ras signaling pathway include the use of RNA-directed genesilencing strategies, such as antisense therapy and RNA interference. Antisense therapy involves the use of oligonucleotides that have sequences complementary to a specific target messenger RNA (mRNA), which, therefore, block its translation to protein. In a phase II trial of patients with locally advanced and metastatic pancreatic cancers, the antisense inhibitor of another member of the Ras family (HRas), ISIS 2503, showed a response rate of $10.4 \%$ and a median survival of 6.6 months in combination with gemcitabine. 13 However, initial enthusiasm for this approach is diminishing following the failures of antisense inhibitors such as ISIS 3521 and oblimersen in lung cancer and melanoma, respectively. An alternative method is RNA interference, which involves the manufacture of small interfering RNAs (siRNAs) that are specific for a particular target mRNA. These siRNAs bind to a complex of several proteins, including endoribonucleases, which is then termed the RNAinduced silencing complex. This complex identifies complementary mRNA and effects its cleavage or translational block. This technology is highly specific but has yet to enter clinical trials, although in vitro and in vivo studies have been promising.14,15

MAP2K, the principal downstream component of Ras signaling, has also been the subject of targeted inhibition. In a phase II trial, the inhibitor CI-1040 (PD184532) did not demonstrate enough antitumor activity to justify further development.16 Nevertheless, combined inhibition of MAP2K and other kinases (such as EGFR) has been effective in preclinical studies, which suggests that this approach might still have a role in therapy for pancreatic cancer. 17,18

The epidermal growth factor receptor pathway-EGFR is a transmembrane receptor tyrosine kinase of the ErbB family. Upon binding to its ligands, homodimerization or heterodimerization with other members of the ErbB family occurs, which leads to phosphorylation of tyrosine residues in its intracellular domain. This process recruits intracellular proteins that cause downstream signaling events through MAPK, PI3K-Akt, and the STAT family of proteins (Figure 2). STAT proteins have roles in cell proliferation, survival, motility, invasion and adhesion. Mechanisms that lead to inappropriate activation of EGFR include receptor overexpression, activating mutations, overexpression of receptor ligands, and/or loss of their negative regulatory pathways. Overexpression of EGFR and its ligands EGF and TGF-a are frequently observed in pancreatic cancer.19,20

In a phase III trial in combination with gemcitabine, erlotinib, an orally active small molecule that binds to the ATP-binding site of EGFR, has demonstrated a small but statistically significant increase in the survival of patients with advanced pancreatic cancer (Table 2).21 In 2005, erlotinib was the first targeted therapy approved by the FDA for pancreatic cancer. However, its clinical significance has been criticized and its costeffectiveness has been questioned.22 Other EGFR tyrosine kinase inhibitors that have been tested in early-phase clinical trials include gefitinib23-25 and lapatinib.26,27

Although EGFR inhibitors have shown promising results, inhibition of EGFR using the monoclonal antibody cetuximab was ineffective in a phase III trial in patients with locally advanced and metastatic pancreatic cancers (Table 2).28 No objective responses were seen in phase II trials of cetuximab in combination with gemcitabine and intensity-modulated radiotherapy or cisplatin.29,30 A phase II trial of cetuximab in combination with docetaxel and irinotecan is ongoing. 31 
Gastrin and cholecystokinin receptor pathway-The peptide hormone gastrin is secreted by $\mathrm{G}$ cells in the gastric antrum and duodenum, and it can act as a growth factor for gastric, colonic and pancreatic cancers. CCK-BR (the gastrin and cholecystokinin receptor), gastrin precursors and the fully amidated gastrin are expressed in 95\%, 55-91\% and 23\% of pancreatic cancers, respectively.32 A selective CCK-BR antagonist, gastrazole, was tested in two small, randomized, controlled trials in patients with advanced pancreatic cancer (Table 2).33 Gastrazole was superior to placebo, but not to 5-fluorouracil. Another inhibitor, the orally active Z-360, has demonstrated promising laboratory results 34 and is tolerated well by patients in combination with gemcitabine.35 A phase III trial of Z-360 is being planned. An alternative approach to blockade of this pathway involves the use of gastrimmune, an immunogen that stimulates the formation of antibodies against gastrin 17 and its precursors. This agent was, however, not successful in a phase III trial (Table 2).36

\section{Angiogenesis}

Angiogenesis is essential for solid tumor growth, and is principally mediated by the vascular endothelial growth factor (VEGF) family of proteins and receptors (Figure 2). Stimuli that upregulate VEGF expression include hypoxia, other growth factors and oncogenic proteins (for example, TGF- $\beta$, EGF and Ras). VEGF is overexpressed in $>90 \%$ of pancreatic cancers 37 and is, therefore, an appealing target for therapy.

Bevacizumab is a humanized antibody against VEGF and is approved for use in patients with colorectal cancer. However, a phase III trial in advanced pancreatic cancer failed to show any survival benefit for bevacizumab in combination with gemcitabine (Table 2). 38 The AVITA (BO17706) phase III study of patients with metastatic pancreatic cancer reported that the addition of bevacizumab to gemcitabine and erlotinib did not significantly prolong overall survival, although a significant improvement in progression-free survival was seen (Table 2).39 A number of other trials are being conducted to examine bevacizumab in combination with other agents or treatment modalities for pancreatic cancer; however, this agent seems unlikely to confer sufficient benefit to justify its licensing for this condition.

The failure of bevacizumab in therapeutic trials for pancreatic cancer highlighted the need for angiogenic inhibitors that could target other non-VEGF pathways and have better access to the tumor environment than an antibody. Sorafenib is a multitargeted kinase inhibitor that inhibits the VEGF receptor (VEGFR), platelet-derived growth factor receptor (PDGFR), SCFR (formerly c-KIT), Raf1 and FLT3, which are all implicated in tumor growth and angiogenesis. Sorafenib was approved in 2005 for the treatment of advanced renal-cell carcinoma. However, a phase II study concluded that, although well-tolerated, it was inactive in patients with advanced pancreatic cancer.40 Axitinib is an orally active inhibitor of both VEGFR and related tyrosine kinase receptors at high concentrations. A median survival of 6.9 months was reported for axitinib combined with gemcitabine compared with 5.6 months for gemcitabine alone in a phase II trial in patients with advanced pancreatic cancer, but this finding was not statistically significant.41 Phase III trials of axitinib combined with gemcitabine are currently in progress. Aflibercept, a recombinant fusion protein that functions as a soluble decoy receptor and thereby inhibits VEGF, is another novel agent being tested in a phase III trial of patients treated with gemcitabine for metastatic pancreatic cancer.

Integrin receptors on the cell surface interact with the extracellular matrix and mediate various signaling pathways (Figure 2). These receptors are involved in many neoplastic processes, including tumor survival, invasion and metastasis. The $\alpha^{\mathrm{V}} \beta^{3}$ and $\mathrm{a}^{\mathrm{V}} \beta^{5}$ integrins induce angiogenesis, principally via basic fibroblast growth factor and VEGF, respectively. Cilengitide inhibits these integrins, but in a phase II trial in patients with advanced 
pancreatic cancer it did not show significant benefit compared to gemcitabine alone. 42 Other anti-integrin agents, including an antibody against $\alpha^{5} \beta^{1}$ (volociximab) 43 and an inhibitor of a 2 (E7820),44 are in early-phase clinical trials.

\section{Matrix metalloproteinases}

Matrix metalloproteinases (MMPs) are a family of zinc-dependent proteolytic enzymes that degrade the extracellular matrix and are essential for tumor spread and neovascularization. We should not, therefore, be surprised that imbalance between MMPs and their natural inhibitors is a frequent event in pancreatic cancer. Despite promising laboratory results, MMP inhibitors have failed to live up to their initial therapeutic expectation in three phase III clinical trials (Table 2),45-47 although critics argued that the trials included a large number of patients with metastatic disease, which contradicts the rationale of exploiting the cytostatic effect of MMP inhibitors.

\section{Other potential therapeutic targets}

\section{Signal-transduction pathways}

The PI3K and Akt Pathway-Upon activation by Ras or EGFR, PI3K activates Akt, which in turn has multiple downstream targets, including the mammalian target of rapamycin (mTOR) and the transcription factor NFkB (Figure 2). mTOR and NFkB have a variety of roles in cell proliferation, survival, resistance to apoptosis, angiogenesis and invasion. AKT2 is amplified and the PI3K-Akt pathway is activated in 20\% and 59\% of pancreatic cancers, respectively.48,49 Deregulation of this pathway through aberrant expression of PTEN (phosphatase and tensin homolog, a natural antagonist of PI3K) is frequently observed in pancreatic cancer.50 Furthermore, an architectural transcription factor, HMGA1, is overexpressed in pancreatic cancer.51 This transcription factor activates PI3K-Akt signaling and seems to mediate resistance to gemcitabine,52 which, therefore, provides another target for inhibition therapy.53,54

Temsirolimus is an mTOR inhibitor approved for the treatment of renal-cell carcinoma, but use of this agent in pancreatic cancer has been limited.55 Other agents, including everolimus and sirolimus, are currently in phase II clinical trials.56 A combination of an mTOR inhibitor with other standard or targeted therapies might be needed,57,58 as mTOR expression does not correlate with survival of patients.59

Curcumin, which is derived from the spice turmeric, can inhibit $\mathrm{NF \kappa B}$ and, therefore, the expression of regulated gene products such as Bcl2, BclXL, COX2, cyclin D1 and survivin, which all have a role in the survival of pancreatic cancer cells.60,61 Curcumin can also alter the expression of miRNAs (microRNAs, see below) in pancreatic cancer cells.62 Phase II trials of curcumin with and without gemcitabine showed that curcumin was well-tolerated and might have some biological activity in patients with pancreatic cancer.63,64 The oral inhibitor of NFKB-STAT3, RTA 402, is being examined in a phase I-II trial. Bortezomib is a proteosome inhibitor that prevents the degradation of $\operatorname{I} \kappa B \beta$, which in turn is an endogenous inhibitor of NFKB (Figure 2). Bortezomib is licensed for the treatment of refractory multiple myeloma, but unfortunately it failed to show any benefit-either alone or in combination with gemcitabine-in a phase II trial.65 This finding could be related to the fact that proteosome inhibition paradoxically activates other antiapoptotic and mitogenic signaling pathways in pancreatic cancer.66

The cyclo-oxygenase pathway-The COX enzymes have a principal role in the conversion of arachidonic acid into prostaglandins. COX1 is constitutively expressed and has a homeostatic role. $\mathrm{COX} 2$ is inducible by growth factors, cytokines and tumor 
promoters, and its expression is upregulated in $90 \%$ of pancreatic cancers. 67 The mechanisms of COX-mediated and prostaglandin-mediated pancreatic-cancer development are complex; they involve multiple mitogenic signaling pathways and molecules that mediate resistance to apoptosis, cell migration, invasion, angiogenesis, immunosuppression, the production of free radicals and peroxidation of procarcinogens to carcinogens. 68 Inhibition of COX2 by NSAIDs suppressed proliferation of pancreatic cancer cells and angiogenesis, both in vitro and in vivo.68,69 Interestingly, Chuang and colleagues reported in 2008 that the antitumor activity of celecoxib does not correlate with its inhibition of COX2, which suggests the involvement of alternative mechanisms.70 Nonetheless, phase II trials of gemcitabine in combination with celecoxib $400 \mathrm{mg}$ twice daily have been conducted, but results were inconclusive. For 20 evaluable patients with metastatic pancreatic cancer, the reported median survival was 6.2 months and the 3-month survival was $72 \% .71$ For patients with locally advanced or metastatic disease, one study showed a median survival of 9.1 months and overall clinical response of $54.7 \%, 72$ but another study concluded that the addition of celecoxib had no significant benefit. 73 The combination of celecoxib, gemcitabine and irinotecan resulted in a median survival of 13 months and 1-year survival of $64 \%$, and was associated with improvement of pain and quality of life.74 A phase III trial of gemcitabine, celecoxib and curcumin is in progress.

The TGF- $\beta$ and SMAD4 pathway-TGF- $\beta$ is a cytokine secreted by epithelial, endothelial, hematopoietic and mesenchymal cells. Binding of TGF- $\beta$ forms a heteromeric complex with the type I and type II TGF- $\beta$ receptors that triggers the phosphorylation of cytoplasmic SMAD2 and SMAD3. In turn, these SMAD proteins form a complex with SMAD4, which translocates into the nucleus to activate gene transcription (Figure 2). TGF$\beta$ can also signal via SMAD-independent pathways that involve Ras, PI3K and MAPK. TGF- $\beta$ mediates a wide range of physiological processes, such as embryonic development, tissue repair, angiogenesis and immunosuppression. TGF- $\beta$ also has a complex role in tumorigenesis, as it is tumor-suppressive in epithelial cells, but promotes invasion and metastasis during the late stages of cancer progression. Mutations of the TGFBR1, TGFBR2 and $S M A D 4$ genes are found in about $1 \%, 4 \%$ and $50 \%$ of pancreatic cancers, respectively. 75 Inactivation of SMAD4 abolishes TGF- $\beta$-mediated tumor-suppressive functions while it maintains some tumor-promoting TGF- $\beta$ responses, such as epithelial-mesenchymal transition, which makes cells migratory and invasive.76

TGF- $\beta$-based therapeutic strategies are currently in development, including inhibitors of TGFBR1 and TGFBR2.77,78 AP 12009, an antisense oligonucleotide specific to TGF- $\beta 2$, is currently being tested in a phase I-II study of malignant melanoma, pancreatic cancer and colorectal carcinomas. One patient with advanced pancreatic cancer was still alive 128 weeks after complete regression of liver metastases.79

The hepatocyte growth factor receptor pathway-The MET oncogene encodes the receptor for hepatocyte growth factor (HGF) and is overexpressed in $78 \%$ of pancreatic cancers. $80 \mathrm{HGF}$ is normally produced by mesenchymal cells and acts on epithelial cells to promote tissue regeneration. In hypoxic conditions, however, tumor-associated fibroblasts produce HGF, which stimulates angiogenesis, tumor growth, enhanced cell motility and extracellular matrix breakdown and leads to invasion and metastasis (Figure 2). Targeting the HGF pathway with use of a synthetic competitive antagonist of HGF81,82 and an antibody against the MET receptor83 has yielded encouraging results in the laboratory setting. ARQ 197 is a MET receptor tyrosine kinase inhibitor that is currently being tested in a phase II trial. A phase I study showed that it was tolerated well by patients. 84

The insulin-like growth factor pathway-The insulin-like growth factor I (IGF-I) receptor, a transmembrane receptor tyrosine kinase, is overexpressed in $64 \%$ of pancreatic 
cancers. 85 The IGF-I receptor has antiapoptotic and growth-promoting effects and acts via multiple signaling cascades, including the PI3-Akt, MAPK and STAT pathways (Figure 2). Inhibition of the IGF-I receptor by the tyrosine kinase inhibitor NVP-AEW541, a dominantnegative mutant and RNA interference have all been shown to reduce the growth of pancreatic cancer cells in vitro and in vivo, and increase chemotherapy-induced or radiationinduced apoptosis.86,87 Concomitant inhibition of KRas increases the therapeutic effect of IGF-I receptor antisense oligonucleotide. 88 Human anti-IGF-I receptor antibodies have been reported to enhance the antitumor effects of gemcitabine and EGFR inhibition in vivo.89,90 As a result of these findings, phase I-II trials of cixutumumab and MK-0646 with gemcitabine and erlotinib have now commenced for pancreatic cancer.

The focal adhesion kinase pathway-Focal adhesion kinase (FADK) is a cytoplasmic non-receptor tyrosine kinase that mediates functions involved in cell motility and survival and is closely related to the integrin signaling pathway (Figure 2). $48 \%$ of pancreatic cancers91 express FADK and, importantly, it shares a common pathway with IGF-I receptor.92 The dual IGF-I receptor-FADK inhibitor NVP-TAE226 has shown significant tumor-suppressive activity in vivo.93

The Src pathway-Src is one of nine members of the Src family of non-receptor protein tyrosine kinases. In normal conditions, Src is maintained in a phosphorylated and inactive form, but is activated in a number of malignancies, including in $70 \%$ of pancreatic cancers. $85 \mathrm{Src}$ has diverse roles in cell proliferation, survival, motility, invasiveness, resistance to chemotherapy and angiogenesis. This protein acts via multiple signaling pathways and, therefore, is an ideal target for therapeutic intervention (Figure 2). Src kinase inhibitors have been effective in suppressing pancreatic tumor growth and metastasis in vivo.94-96 Dasatinib is an orally active multitargeted kinase inhibitor of Src, BCR-ABL, PDGFR, ephrin type A receptor 2 and SCFR, and is licensed for the treatment of chronic myelogenous and acute lymphoblastic leukemias. Dasatinib is being examined in a phase II trial in patients with metastatic pancreatic cancer, as is the related compound saracatinib.

\section{Embryonic signaling pathways}

The hedgehog pathway-Three mammalian hedgehog homolog proteins have been identified-DHH, IHH and SHH. These proteins are secreted and specify the organization and structure of many tissues during embryonic development. Activation of the hedgehog signaling pathway is controlled by two transmembrane proteins, the tumor-suppressor PTC1 protein and the oncogenic SMO protein (Figure 2). PTC1 normally suppresses SMO, but mechanisms, such as an inactivating mutation of PTC1 and the binding of hedgehog proteins to PTC1, relieves this inhibition, which leads to SMO activation of transcriptional responses. SHH is expressed in $70 \%$ of human pancreatic adenocarcinomas.97 IHH expression is increased 35-fold in pancreatic cancer cells compared with normal tissues.98 Mechanisms of tumorigenesis include the effects of hedgehog proteins on the cell-cycle regulators, protection from apoptosis via PI3K-Akt signaling and stabilization of Bcl2 and BclXL and collaboration with activated KRas and angiogenesis. The hedgehog signaling pathway can be inhibited by cyclopamine, which binds to SMO. Laboratory work has demonstrated the effectiveness of cyclopamine in a wide range of digestive-tract tumors, including pancreatic cancer.99 Cyclopamine can enhance sensitivity to radiotherapy and chemotherapy and suppress metastatic spread100,101 as well as improving antitumor activity when combined with an EGFR inhibitor.102 A downstream target of the SHH pathway, the transcription factor GLI 1, can also be inhibited by miRNA.103

The Notch pathway-The four known human Notch genes encode heterodimeric transmembrane receptors, which are important in the development of organs, tissue 
proliferation, differentiation and apoptosis. Activation of the Notch signaling pathway leads to proteolytic cleavage of the transmembrane receptors by $\gamma$-secretase; the released cytoplasmic domain then migrates to the nucleus and binds to transcription factors, which leads to the expression of a variety of genes (Figure 2). Notch signaling occurs downstream of Ras, EGFR and TGF-a signaling in pancreatic tumorigenesis and promotes tumor vascularization. Downregulation of Notch 1 with siRNA or curcumin (owing to the crosstalk between Notch and NFKB signaling pathways) can inhibit cell growth and induce apoptosis in pancreatic cancer cell lines in vitro.104,105 Notch 3 is expressed in around 70\% of pancreatic cancers and can be inhibited by siRNA and $\gamma$-secretase inhibitor (L-685,458). 106,107

The Wnt pathway-19 human Wnt genes each encodes a lipid-modified secreted glycoprotein. Wnt signaling is involved in normal embryonic development and homeostatic self-renewal of a number of adult tissues. Three Wnt signaling cascades, namely the canonical Wnt- $\beta$-catenin, the planar-cell polarity, and the Wnt- $\mathrm{Ca}^{2+}$ pathways. The former is the best known and has been implicated in a variety of cancers including liver, colorectal, breast, prostate, renal and hematological malignancies. Normally $\beta$-catenin is phosphorylated and targeted for degradation. However, binding of Wnt proteins results in activation of intracellular pathways that cause $\beta$-catenin to enter the nucleus, where its interaction with the T-cell factor (TCF) and lymphoid enhancer factor (LEF) families of transcription factors leads to targeted gene expression (Figure 2). Any gain-of-function mutation of activators or loss-of-function mutation of inhibitors of Wnt signaling could lead to aberrant activation of these signaling pathways, which could result in carcinogenesis and progression. Aberrant activation occurs in 65\% of pancreatic cancers. 108 Inhibition of Wnt signaling to reduce proliferation and increase apoptosis of pancreatic cancer cells has been achieved in the laboratory setting by a variety of methods, including the use of $\beta$-catenininteracting protein 1 , a dominant-negative mutant of LEF-1, and siRNA against $\beta$-catenin or extracellular sulfatases.109,110 Wnt signaling is positively regulated by the hedgehog and SMAD4 signaling pathways, 109,111 which could be targets for a combined inhibitory therapeutic strategy.

The chemokine receptor 4 (CXCR 4) and its ligand, SDF-1 have a role in tumor growth, angiogenesis and, in particular, metastatic spread. In vitro blockade of CXCR 4 could inhibit pancreatic cancer growth through inhibition of the canonical Wnt pathway.112 Furthermore, plerixafor, an antagonist of CXCR 4, reduces metastasis by pancreatic cancer cells that are positive for the markers CXCR 4 and CD133 (the latter is a marker of pancreatic cancer stem cells) in vivo. 113

\section{Telomerase}

The telomeres located at the end of chromosomes normally shrink with each cell division and thereby impose a finite lifespan on the cell. Most malignant cells have detectable activity of telemerase, a reverse transcriptase that contains an RNA template and acts to elongate telomeres. Telomerase is overexpressed in $95 \%$ of pancreatic cancers 114 which provides a rationale for the development of antitelomerase agents. GV1001 is a telomerase peptide vaccine that has shown some promising results in phase I/II studies.115,116 This vaccine is being tested in the large (>1,000 patients), phase III, TeloVac trial with gemcitabine and capecitabine in locally advanced and metastatic pancreatic cancers.

\section{MicroRNAs}

The miRNAs are small, endogenous, noncoding RNA molecules that regulate gene expression and are important for developmental and physiological processes. These molecules all negatively regulate gene expression post-transcriptionally and can be either 
oncogenic or tumor-suppressive, depending on their target mRNAs.117 Expression profiling showed that at least 100 miRNA precursors are aberrantly expressed in pancreatic cancer or desmoplasia.118,119 Anticancer miRNA-based therapy has the theoretical advantage of having multiple targets that are controlled by an individual miRNA by virtue of its posttranscriptional modulation. Therapeutic strategies include the reconstitution of tumorsuppressive miRNAs and the knockdown of oncogenic miRNAs by coding vectors or antimiRNA oligonucleotides. Studies of these treatment approaches have been limited in pancreatic cancer but have yielded promising results in breast cancer and glioma.

\section{Cancer stem cells}

Cancer stem cells possess important properties associated with their normal counterparts, namely the ability for self-renewal and differentiation. Pancreatic-cancer stem cells are identified by their surface markers, such as CD133, CD44, CD24 and flotillin 2 epithelial specific-antigen. Evidence suggests that such cells form a small subset in the heterogenous tumor population, and contribute to neoplastic progression, metastasis and resistance to chemotherapy and radiotherapy.113,120 For this reason, cancer stem cells are thought to be responsible for relapse of disease after clinical remission. Dysregulation of various signaling cascades, including the PTEN, SHH, Notch and Wnt pathways, are frequently observed in cancer stem cells, which provides further rationale for use of these pathways as a target for therapeutic purposes. Further studies are still needed to understand the genetic and biological properties of cancer stem cells for the development of effective treatment modalities.

\section{Conclusions}

Although targeted therapies for pancreatic cancer have yielded encouraging results in vitro and in animal models, these findings have not been translated to improved outcomes in clinical trials. Reasons for this failure might include an incomplete understanding of the biology of pancreatic cancer, the selection of poor active agents, problems with trial design (such as inappropriate therapeutic end points or patient selection) and the rapidity with which agents move into randomized, controlled trials without the extensive early testing necessary to optimize treatment regimens. Furthermore, preclinical studies performed on mouse models do not always recapitulate the human condition, which is a particular problem with human pancreatic cancer xenografts in immunodeficient mice. Despite these setbacks, lessons have been learnt, and our collective effort has generated a substantial platform of knowledge from which further work could spring. Genetically engineered immunocompetent mice, such as those with KRAS or TP53 mutations, have been developed and they hold promise for the future studies of the disease.121 The bioavailability of compounds such as antisense oligonucleotides and siRNAs in humans remains a big hurdle, which will require further improvement of gene-delivery strategies.

The individualization of therapy for patients is possible if factors that predict treatment response, such as biological markers, could be determined accurately. Alternatively, resected tumors could be grown in laboratory mice and treated with a series of drugs, and the most effective agent subsequently administered to the patient. This concept is currently being tested in a phase II trial at Johns Hopkins Hospital, MD, US. Until this strategy is proven effective in the clinical setting, multimodal approaches will remain the mainstay of treatment for advanced pancreatic cancer. These approaches are likely to comprise a mixture of targeted agents in combination with conventional chemotherapy and radiotherapy. For a clinically significant effect to be achieved, treatment strategies should either be in the form of a 'horizontal' approach, in which several oncogenic pathways are inhibited, or a 'vertical' approach, whereby multiple levels of a major pathway are targeted. One example currently being investigated in a phase III trial is the treatment combination of celecoxib, curcumin 
and gemcitabine for advanced pancreatic cancer. Besides the synergistic antiproliferative and proapoptotic effects of curcumin and celecoxib,122 these agents also potentiate the antitumor activity of gemcitabine.123,124 Combination therapies, together with improved diagnostic tools and predictive markers, are ultimately hoped to improve the bleak outlook for patients diagnosed with pancreatic cancer. For now, the results of a number of phase III trials are eagerly awaited (Table 3).

\section{Review criteria}

PubMed was searched in November 2008 for English-language publications using the terms "pancreatic", "pancreas", "carcinoma", "cancer", "therapy", "treatment" and those listed in the article subheadings. Published reports and abstracts from the American Society of Clinical Oncology and the American Association for Cancer Research meetings, were also searched. No exclusion criteria were used. Articles were selected on the basis of relevance and additional papers were identified from their reference lists. The National Cancer Institute website was searched for ongoing clinical trials.

\section{Key points}

Pancreatic cancer is a disease that has high morbidity and mortality and is resistant to conventional treatment; therefore, an unmet need for novel therapeutic approaches exists

Important molecular pathways and components involved in pancreatic carcinogenesis have been targeted with therapeutic intent, including Ras, EGFR, VEGF, gastrin and matrix metalloproteinases

Good results from novel therapies have been demonstrated in vitro and in animal models, but results from the limited number of clinical trials are less encouraging

Erlotinib, an EGFR tyrosine kinase inhibitor, is the only agent so far that has shown a significant (albeit small) survival benefit in a phase III clinical trial

Potential therapeutic targets that warrant further investigation include other signaltransduction and embryonic pathways, telomerase, microRNAs and cancer stem cells

Future development of targeted treatments should focus on inhibition of multiple signaling pathways, or blockade of one signaling pathway at multiple levels

\section{References}

1. Jemal A, et al. Cancer statistics, 2008. CA Cancer J. Clin. 2008; 58:71-96. [PubMed: 18287387]

2. Pancreatic section, British Society of Gastroenterology. et al. Guidelines for the management of patients with pancreatic cancer periampullary and ampullary carcinomas. Gut. 2005; 54(Suppl. 5):v1-v16. [PubMed: 15888770]

3. Burris HA 3rd, et al. Improvements in survival and clinical benefit with gemcitabine as first-line therapy for patients with advanced pancreas cancer: a randomized trial. J. Clin. Oncol. 1997; 15:2403-2413. [PubMed: 9196156]

4. Jones $\mathrm{S}$, et al. Core signaling pathways in human pancreatic cancers revealed by global genomic analyses. Science. 2008; 321:1801-1806. [PubMed: 18772397]

5. Almoguera $\mathrm{C}$, et al. Most human carcinomas of the exocrine pancreas contain mutant c-K-ras genes. Cell. 1988; 53:549-554. [PubMed: 2453289]

6. Toubaji A, et al. Pilot study of mutant Ras peptide-based vaccine as an adjuvant treatment in pancreatic and colorectal cancers. Cancer Immunol. Immunother. 2008; 57:1413-1420. [PubMed: 18297281] 
7. Gjertsen MK, et al. Intradermal Ras peptide vaccination with granulocyte-macrophage colonystimulating factor as adjuvant: clinical and immunological responses in patients with pancreatic adenocarcinoma. Int. J. Cancer. 2001; 92:441-450. [PubMed: 11291084]

8. Achtar MS, et al. Phase II clinical trial of mutant Ras peptide vaccine in combination with GM-CSF and IL-2 in advanced cancer patients [Abstract]. J. Clin. Oncol. 2007; 25:a3067.

9. Van Cutsem E, et al. Phase III trial of gemcitabine plus tipifarnib compared with gemcitabine plus placebo in advanced pancreatic cancer. J. Clin. Oncol. 2004; 22:1430-1438. [PubMed: 15084616]

10. Martin NE, et al. A phase I trial of the dual farnesyltransferase and geranylgeranyltransferase inhibitor L-778, 123 and radiotherapy for locally advanced pancreatic cancer. Clin. Cancer Res. 2004; 10:5447-5454. [PubMed: 15328183]

11. Doss $\mathrm{HH}$, et al. A phase I trial of romidepsin in combination with gemcitabine in patients with pancreatic and other advanced solid tumors [Abstract]. J. Clin. Oncol. 2008; 26:a2567.

12. Rudek MA, et al. Integrated development of s-trans,trans-farnesylthiosalicylic acid (FTS, salirasib) in pancreatic cancer [Abstract]. J. Clin. Oncol. 2008; 26:a4626.

13. Alberts SR, et al. Gemcitabine and ISIS-2503 for patients with locally advanced or metastatic pancreatic adenocarcinoma: a North Central Cancer Treatment Group phase II trial. J. Clin. Oncol. 2004; 22:4944-4950. [PubMed: 15611509]

14. Rejiba S, Wack S, Aprahamian M, Hajri A. K-ras oncogene silencing strategy reduces tumor growth and enhances gemcitabine chemotherapy efficacy for pancreatic cancer treatment. Cancer Sci. 2007; 98:1128-1136. [PubMed: 17489984]

15. Brummelkamp TR, Bernards R, Agami R. Stable suppression of tumorigenicity by virus-mediated RNA interference. Cancer Cell. 2002; 2:243-247. [PubMed: 12242156]

16. Rinehart J, et al. Multicenter phase II study of the oral MEK inhibitor, CI-1040, in patients with advanced non-small-cell lung, breast, colon, and pancreatic cancer. J. Clin. Oncol. 2004; 22:44564462. [PubMed: 15483017]

17. Jimeno A, et al. Dual mitogen-activated protein kinase and epidermal growth factor receptor inhibition in biliary and pancreatic cancer. Mol. Cancer Ther. 2007; 6:1079-1088. [PubMed: 17363501]

18. Takayama Y, et al. MEK inhibitor enhances the inhibitory effect of imatinib on pancreatic cancer cell growth. Cancer Lett. 2008; 264:241-249. [PubMed: 18346844]

19. Korc M, et al. Overexpression of the epidermal growth factor receptor in human pancreatic cancer is associated with concomitant increases in the levels of epidermal growth factor and transforming growth factor alpha. J. Clin. Invest. 1992; 90:1352-1360. [PubMed: 1401070]

20. Bloomston M, Bhardwaj A, Ellison EC, Frankel WL. Epidermal growth factor receptor expression in pancreatic carcinoma using tissue microarray technique. Dig. Surg. 2006; 23:74-79. [PubMed: 16717472]

21. Moore MJ, et al. Erlotinib plus gemcitabine compared with gemcitabine alone in patients with advanced pancreatic cancer: a phase III trial of the National Cancer Institute of Canada Clinical Trials Group. J. Clin. Oncol. 2007; 25:1960-1966. [PubMed: 17452677]

22. Grubbs SS, Grusenmeyer PA, Petrelli NJ, Gralla RJ. Is it cost-effective to add erlotinib to gemcitabine in advanced pancreatic cancer? [Abstract]. J. Clin. Oncol. 2006; 24:a6048.

23. Fountzilas G, et al. Gemcitabine combined with gefitinib in patients with inoperable or metastatic pancreatic cancer: a phase II study of the Hellenic Cooperative Oncology Group with biomarker evaluation. Cancer Invest. 2008; 26:784-793. [PubMed: 18798073]

24. Ignatiadis $\mathrm{M}$, et al. A multicenter phase II study of docetaxel in combination with gefitinib in gemcitabine-pretreated patients with advanced/metastatic pancreatic cancer. Oncology. 2006; 71:159-163. [PubMed: 17646699]

25. Blaszkowsky LS, et al. A phase II study of docetaxel in combination with ZD1839 (gefitinib) in previously treated patients with metastatic pancreatic cancer [Abstract]. J. Clin. Oncol. 2007; 25:a15080.

26. Safran H, et al. Lapatinib/gemcitabine and lapatinib/gemcitabine/oxaliplatin: a phase I study for advanced pancreaticobiliary cancer. Am. J. Clin. Oncol. 2008; 31:140-144. [PubMed: 18391597] 
27. Midgley R, et al. Phase I study of GW572016 (lapatinib), a dual kinase inhibitor, in combination with irinotecan (IR), 5-fluorouracil (FU) and leucovorin (LV). J. Clin. Oncol. 2005; 23:30863093. [PubMed: 15860868]

28. Philip PA, et al. Phase III study of gemcitabine [G] plus cetuximab [C] versus gemcitabine in patients [pts] with locally advanced or metastatic pancreatic adenocarcinoma [PC]: SWOG S0205 study [Abstract]. J. Clin. Oncol. 2007; 25:a4509.

29. Cascinu S, et al. Cetuximab plus gemcitabine and cisplatin compared with gemcitabine and cisplatin alone in patients with advanced pancreatic cancer: a randomised, multicentre, phase II trial. Lancet Oncol. 2008; 9:39-44. [PubMed: 18077217]

30. Munter M, et al. Final results of a phase II trial [PARC-Study ISRCTN56652283] for patients with primary inoperable locally advanced pancreatic cancer combining intensity modulated radiotherapy (IMRT) with cetuximab and gemcitabine [Abstract]. J. Clin. Oncol. 2008; 26:a4613.

31. Burtness BA, et al. Phase II ECOG trial of irinotecan/docetaxel with or without cetuximab in metastatic pancreatic cancer: updated survival and CA19-19 results [Abstract]. J. Clin. Oncol. 2008; 26:a4642.

32. Caplin M, et al. Expression and processing of gastrin in pancreatic adenocarcinoma. Br. J. Surg. 2000; 87:1035-1040. [PubMed: 10931047]

33. Chau I, et al. Gastrazole (JB95008), a novel CCK2/gastrin receptor antagonist, in the treatment of advanced pancreatic cancer: results from two randomised controlled trials. Br. J. Cancer. 2006; 94:1107-1115. [PubMed: 16622436]

34. Kawasaki D, et al. Effect of Z-360, a novel orally active CCK-2/gastrin receptor antagonist on tumor growth in human pancreatic adenocarcinoma cell lines in vivo and mode of action determinations in vitro. Cancer Chemother. Pharmacol. 2008; 61:883-892. [PubMed: 17901954]

35. Meyer T, et al. A phase IB/IIA, multicentre, randomised, double-blind placebo controlled study to evaluate the safety and pharmacokinetics of Z-360 in subjects with unresectable advanced pancreatic cancer in combination with gemcitabine [Abstract]. J. Clin. Oncol. 2008; 26:a4636.

36. Shapiro J, et al. G17DT + gemcitabine [Gem] versus placebo + Gem in untreated subjects with locally advanced, recurrent, or metastatic adenocarcinoma of the pancreas: results of a randomized, double-blind, multinational, multicenter study [Abstract]. J. Clin. Oncol. 2005; 23:a4012.

37. Seo Y, Baba H, Fukuda T, Takashima M, Sugimachi K. High expression of vascular endothelial growth factor is associated with liver metastasis and a poor prognosis for patients with ductal pancreatic adenocarcinoma. Cancer. 2000; 88:2239-45. [PubMed: 10820344]

38. Kindler HL, et al. A double-blind, placebo-controlled, randomized phase III trial of gemcitabine (G) plus bevacizumab (B) versus gemcitabine plus placebo (P) in patients (pts) with advanced pancreatic cancer (PC): a preliminary analysis of Cancer and Leukemia Group B (CALGB). J. Clin. Oncol. 2007; 25:4508-4509. [PubMed: 17906219]

39. Vervenne W, et al. A randomized, double-blind, placebo (P) controlled, multicenter phase III trial to evaluate the efficacy and safety of adding bevacizumab $(B)$ to erlotinib $(\mathrm{E})$ and gemcitabine $(\mathrm{G})$ in patients (pts) with metastatic pancreatic cancer. J. Clin. Oncol. 2008; 26:4507-4509. [PubMed: 18802163]

40. Wallace JA, et al. Sorafenib (S) plus gemcitabine $(\mathrm{G})$ for advanced pancreatic cancer (PC): A phase II trial of the University of Chicago Phase II Consortium [Abstract]. J. Clin. Oncol. 2007; 25:a4608.

41. Spano JP, et al. Efficacy of gemcitabine plus axitinib compared with gemcitabine alone in patients with advanced pancreatic cancer: an open-label randomised phase II study. Lancet. 2008; 371:2101-2108. [PubMed: 18514303]

42. Friess $\mathrm{H}$, et al. A randomized multi-center phase II trial of the angiogenesis inhibitor Cilengitide (EMD 121974) and gemcitabine compared with gemcitabine alone in advanced unresectable pancreatic cancer. BMC Cancer. 2006; 6:285. [PubMed: 17156477]

43. Evans T, et al. Final results from cohort 1 of a phase II study of volociximab, an anti-a $5 \beta 1$ integrin antibody, in combination with gemcitabine (GEM) in patients (pts) with metastatic pancreatic cancer (MPC) [Abstract]. J. Clin. Oncol. 2007; 25:a4549. 
44. Mita MM, et al. Pharmacokinetics (PK) and pharmacodynamics (PD) of E7820 — an oral sulfonamide with novel, a-2 integrin mediated antiangiogenic properties: results of a phase I study [Abstract]. J. Clin. Oncol. 2005; 23:a3082.

45. Bramhall SR, Rosemurgy A, Brown PD, Bowry C, Buckels JA. Marimastat as first-line therapy for patients with unresectable pancreatic cancer: a randomized trial. J. Clin. Oncol. 2001; 19:34473455. [PubMed: 11481349]

46. Bramhall SR, et al. A double-blind placebo-controlled, randomised study comparing gemcitabine and marimastat with gemcitabine and placebo as first line therapy in patients with advanced pancreatic cancer. Br. J. Cancer. 2002; 87:161-167. [PubMed: 12107836]

47. Moore MJ, et al. Comparison of gemcitabine versus the matrix metalloproteinase inhibitor BAY 12-9566 in patients with advanced or metastatic adenocarcinoma of the pancreas: a phase III trial of the National Cancer Institute of Canada Clinical Trials Group. J. Clin. Oncol. 2003; 21:32963302. [PubMed: 12947065]

48. Ruggeri BA, Huang L, Wood M, Cheng JQ, Testa JR. Amplification and overexpression of the $A K T 2$ oncogene in a subset of human pancreatic ductal adenocarcinomas. Mol. Carcinog. 1998; 21:81-86. [PubMed: 9496907]

49. Schlieman MG, Fahy BN, Ramsamooj R, Beckett L, Bold RJ. Incidence, mechanism and prognostic value of activated Akt in pancreas cancer. Br. J. Cancer. 2003; 89:2110-2115. [PubMed: 14647146]

50. Asano T, et al. The PI 3-kinase/Akt signaling pathway is activated due to aberrant Pten expression and targets transcription factors NF- $\mathrm{kB}$ and c-Myc in pancreatic cancer cells. Oncogene. 2004; 23:8571-8580. [PubMed: 15467756]

51. Abe N, et al. Pancreatic duct cell carcinomas express high levels of high mobility group I(Y) proteins. Cancer Res. 2000; 60:3117-3122. [PubMed: 10866296]

52. Liau SS, Whang E. HMGA1 is a molecular determinant of chemoresistance to gemcitabine in pancreatic adenocarcinoma. Clin. Cancer Res. 2008; 14:1470-1477. [PubMed: 18316571]

53. Liau SS, Ashley SW, Whang EE. Lentivirus-mediated RNA interference of HMGA1 promotes chemosensitivity to gemcitabine in pancreatic adenocarcinoma. J. Gastrointest. Surg. 2006; 10:1254-1262. [PubMed: 17114012]

54. Trapasso F, et al. Therapy of human pancreatic carcinoma based on suppression of HMGA1 protein synthesis in preclinical models. Cancer Gene Ther. 2004; 11:633-641. [PubMed: $15272314]$

55. Ito D, et al. In vivo antitumor effect of the mTOR inhibitor CCI-779 and gemcitabine in xenograft models of human pancreatic cancer. Int. J. Cancer. 2006; 118:2337-2343. [PubMed: 16331623]

56. Wolpin BM, et al. Phase II study of RAD001 in previously treated patients with metastatic pancreatic cancer [Abstract]. J. Clin. Oncol. 2008; 26:a4614.

57. Azzariti A, Porcelli L, Gatti G, Nicolin A, Paradiso A. Synergic antiproliferative and antiangiogenic effects of EGFR and mTOR inhibitors on pancreatic cancer cells. Biochem. Pharmacol. 2008; 75:1035-1044. [PubMed: 18191814]

58. Tuncyurek P, et al. Everolimus and mycophenolate mofetil sensitize human pancreatic cancer cells to gemcitabine in vitro: a novel adjunct to standard chemotherapy? Eur. Surg. Res. 2007; 39:380387. [PubMed: 17700025]

59. Rajan A, et al. mTOR expression in pancreatic adenocarcinoma and its correlation with survival [Abstract]. J. Clin. Oncol. 2008; 26:a22169.

60. Reuter S, Eifes S, Dicato M, Aggarwal BB, Diederich M. Modulation of anti-apoptotic and survival pathways by curcumin as a strategy to induce apoptosis in cancer cells. Biochem. Pharmacol. 2008; 76:1340-1351. [PubMed: 18755156]

61. Wang Z, et al. Synergistic effects of multiple natural products in pancreatic cancer cells. Life Sci. 2008; 83:293-300. [PubMed: 18640131]

62. Sun M, et al. Curcumin (diferuloylmethane) alters the expression profiles of microRNAs in human pancreatic cancer cells. Mol. Cancer Ther. 2008; 7:464-473. [PubMed: 18347134]

63. Dhillon N, et al. Phase II trial of curcumin in patients with advanced pancreatic cancer. Clin. Cancer Res. 2008; 14:4491-4499. [PubMed: 18628464] 
64. Epelbaum R, Vizel B, Bar-Sela G. Phase II study of curcumin and gemcitabine in patients with advanced pancreatic cancer [Abstracts]. J. Clin. Oncol. 2008; 26:a15619.

65. Alberts SR, et al. PS-341 and gemcitabine in patients with metastatic pancreatic adenocarcinoma: a North Central Cancer Treatment Group (NCCTG) randomized phase II study. Ann. Oncol. 2005; 16:1654-1661. [PubMed: 16085692]

66. Sloss CM, et al. Proteasome inhibition activates epidermal growth factor receptor (EGFR) and EGFR-independent mitogenic kinase signaling pathways in pancreatic cancer cells. Clin. Cancer Res. 2008; 14:5116-5123. [PubMed: 18698029]

67. Tucker ON, et al. Cyclooxygenase-2 expression is up-regulated in human pancreatic cancer. Cancer Res. 1999; 59:987-990. [PubMed: 10070951]

68. Ding XZ, Hennig R, Adrian TE. Lipoxygenase and cyclooxygenase metabolism: new insights in treatment and chemoprevention of pancreatic cancer. Mol. Cancer. 2003; 2:10. [PubMed: 12575899]

69. Wei D, et al. Celecoxib inhibits vascular endothelial growth factor expression in and reduces angiogenesis and metastasis of human pancreatic cancer via suppression of Sp1 transcription factor activity. Cancer Res. 2004; 64:2030-2038. [PubMed: 15026340]

70. Chuang HC, Kardosh A, Gaffney KJ, Petasis NA, Schonthal AH. COX-2 inhibition is neither necessary nor sufficient for celecoxib to suppress tumor cell proliferation and focus formation in vitro. Mol. Cancer. 2008; 7:38. [PubMed: 18485224]

71. Xiong HQ, et al. A phase II trial of gemcitabine and celecoxib for metastatic pancreatic cancer [Abstract]. J. Clin. Oncol. 2005; 23:a4174.

72. Ferrari V, et al. Gemcitabine plus celecoxib (GECO) in advanced pancreatic cancer: a phase II trial. Cancer Chemother. Pharmacol. 2006; 57:185-190. [PubMed: 16151811]

73. Dragovich T, et al. Gemcitabine plus celecoxib in patients with advanced or metastatic pancreatic adenocarcinoma: results of a phase II trial. Am. J. Clin. Oncol. 2008; 31:157-162. [PubMed: 18391600]

74. Kerr S, et al. Phase II trial of gemcitabine and irinotecan plus celecoxib in advanced adenocarcinoma of the pancreas [Absract]. J. Clin. Oncol. 2005; 23:4155.

75. Goggins M, et al. Genetic alterations of the transforming growth factor beta receptor genes in pancreatic and biliary adenocarcinomas. Cancer Res. 1998; 58:5329-5332. [PubMed: 9850059]

76. Levy L, Hill CS. Smad4 dependency defines two classes of transforming growth factor $\beta$ (TGF- $\beta$ ) target genes and distinguishes TGF- $\beta$-induced epithelial-mesenchymal transition from its antiproliferative and migratory responses. Mol. Cell Biol. 2005; 25:8108-8125. [PubMed: 16135802]

77. Melisi D, et al. LY2109761, a novel transforming growth factor beta receptor type I and type II dual inhibitor, as a therapeutic approach to suppressing pancreatic cancer metastasis. Mol. Cancer Ther. 2008; 7:829-840. [PubMed: 18413796]

78. Medicherla S, et al. Antitumor activity of TGF-beta inhibitor is dependent on the microenvironment. Anticancer Res. 2007; 27:4149-4157. [PubMed: 18229422]

79. Hilbig A, et al. Preliminary results of a phase I/II study in patients with pancreatic carcinoma, malignant melanoma, or colorectal carcinoma using systemic i.v. administration of AP 12009 [Abstract]. J. Clin. Oncol. 2008; 26:a4621.

80. Furukawa T, Duguid WP, Kobari M, Matsuno S, Tsao MS. Hepatocyte growth factor and Met receptor expression in human pancreatic carcinogenesis. Am. J. Pathol. 1995; 147:889-895. [PubMed: 7573364]

81. Tomioka D, et al. Inhibition of growth, invasion, and metastasis of human pancreatic carcinoma cells by NK4 in an orthotopic mouse model. Cancer Res. 2001; 61:7518-7524. [PubMed: 11606388]

82. Ogura Y, et al. Peritumoral injection of adenovirus vector expressing NK4 combined with gemcitabine treatment suppresses growth and metastasis of human pancreatic cancer cells implanted orthotopically in nude mice and prolongs survival. Cancer Gene Ther. 2006; 13:520529. [PubMed: 16341142]

83. Jin $\mathrm{H}$, et al. MetMAb, the one-armed 5D5 anti-c-Met antibody, inhibits orthotopic pancreatic tumor growth and improves survival. Cancer Res. 2008; 68:4360-8. [PubMed: 18519697] 
84. Garcia A, et al. Phase 1 study of ARQ 197, a selective inhibitor of the c-Met RTK in patients with metastatic solid tumors reaches recommended phase 2 dose [Abstract]. J. Clin. Oncol. 2007; 25:a3525.

85. Hakam A, Fang Q, Karl R, Coppola D. Coexpression of IGF-1R and c-Src proteins in human pancreatic ductal adenocarcinoma. Dig Dis. Sci. 2003; 48:1972-8. [PubMed: 14627343]

86. Adachi Y, et al. Molecular targeting of IGF-I receptor for human pancreatic cancer [Abstract]. J. Clin. Oncol. 2007; 25:a14051.

87. Piao W, et al. Insulin-like growth factor-I receptor blockade by a specific tyrosine kinase inhibitor for human gastrointestinal carcinomas. Mol. Cancer Ther. 2008; 7:1483-1493. [PubMed: 18566219]

88. Shen YM, Yang XC, Yang C, Shen JK. Enhanced therapeutic effects for human pancreatic cancer by application of K-ras and IGF-IR antisense oligodeoxynucleotides. World J. Gastroenterol. 2008; 14:5176-5185. [PubMed: 18777594]

89. Beltran PJ, et al. Effect of AMG 479 on anti-tumor effects of gemcitabine and erlotinib against pancreatic carcinoma xenograft models. J. Clin. Oncol. 2008; 26:4617-4625. [PubMed: 18678835]

90. Prewett, M., et al. IMC-A12 enhances the efficacy of cetuximab + gemcitabine therapy in human pancreatic carcinoma xenografts in AACR Meeting Abstracts 2007; Philadelphia: The American Association for Cancer Research; 2007. p. 652

91. Furuyama K, et al. Clinical significance of focal adhesion kinase in resectable pancreatic cancer. World J. Surg. 2006; 30:219-226. [PubMed: 16425085]

92. Liu W, et al. FAK and IGF-IR interact to provide survival signals in human pancreatic adenocarcinoma cells. Carcinogenesis. 2008; 29:1096-1107. [PubMed: 18263593]

93. Hatakeyama S, et al. Anti-cancer activity of NVP-TAE226, a potent dual FAK/IGF-IR kinase inhibitor, against pancreatic carcinoma [Abstract]. J. Clin. Oncol. 2006; 24:a13162.

94. Ischenko I, et al. Effect of Src kinase inhibition on metastasis and tumor angiogenesis in human pancreatic cancer. Angiogenesis. 2007; 10:167-182. [PubMed: 17486419]

95. Baker $\mathrm{CH}$, et al. Inhibition of PDGFR phosphorylation and Src and Akt activity by GN963 leads to therapy of human pancreatic cancer growing orthotopically in nude mice. Int. J. Oncol. 2006; 29:125-138. [PubMed: 16773192]

96. Trevino JG, et al. Inhibition of SRC expression and activity inhibits tumor progression and metastasis of human pancreatic adenocarcinoma cells in an orthotopic nude mouse model. Am. J. Pathol. 2006; 168:962-972. [PubMed: 16507911]

97. Thayer SP, et al. Hedgehog is an early and late mediator of pancreatic cancer tumorigenesis. Nature. 2003; 425:851-856. [PubMed: 14520413]

98. Kayed H, et al. Indian hedgehog signaling pathway: expression and regulation in pancreatic cancer. Int. J. Cancer. 2004; 110:668-676. [PubMed: 15146555]

99. Berman DM, et al. Widespread requirement for Hedgehog ligand stimulation in growth of digestive tract tumours. Nature. 2003; 425:846-851. [PubMed: 14520411]

100. Shafaee Z, Schmidt H, Du W, Posner M, Weichselbaum R. Cyclopamine increases the cytotoxic effects of paclitaxel and radiation but not cisplatin and gemcitabine in Hedgehog expressing pancreatic cancer cells. Cancer Chemother. Pharmacol. 2006; 58:765-770. [PubMed: 16552573]

101. Feldmann G, et al. Blockade of hedgehog signaling inhibits pancreatic cancer invasion and metastases: a new paradigm for combination therapy in solid cancers. Cancer Res. 2007; 67:2187-2196. [PubMed: 17332349]

102. Hu WG, Liu T, Xiong JX, Wang CY. Blockade of sonic hedgehog signal pathway enhances antiproliferative effect of EGFR inhibitor in pancreatic cancer cells. Acta Pharmacol. Sin. 2007; 28:1224-1230. [PubMed: 17640486]

103. Chang, DZ. Synthetic miRNAs targeting the GLI-1 transcription factor inhibit division and induce apoptosis in pancreatic tumor cells in AACR Meeting Abstracts 2007; Philadelphia: The American Association for Cancer Research; 2006. p. 639b

104. Wang Z, et al. Down-regulation of Notch-1 contributes to cell growth inhibition and apoptosis in pancreatic cancer cells. Mol. Cancer Ther. 2006; 5:483-493. [PubMed: 16546962] 
105. Wang Z, Zhang Y, Banerjee S, Li Y, Sarkar FH. Notch-1 down-regulation by curcumin is associated with the inhibition of cell growth and the induction of apoptosis in pancreatic cancer cells. Cancer. 2006; 106:2503-2513. [PubMed: 16628653]

106. Dang T, Vo K, Washington K, Berlin J. The role of Notch3 signaling pathway in pancreatic cancer [Abstract]. J. Clin. Oncol. 2007; 25:a21049.

107. Doucas H, et al. Expression of nuclear Notch3 in pancreatic adenocarcinomas is associated with adverse clinical features, and correlates with the expression of STAT3 and phosphorylated Akt. J. Surg. Oncol. 2008; 97:63-68. [PubMed: 17918209]

108. Zeng G, et al. Aberrant Wnt/beta-catenin signaling in pancreatic adenocarcinoma. Neoplasia. 2006; 8:279-289. [PubMed: 16756720]

109. di Magliano, M. Pasca, et al. Common activation of canonical Wnt signaling in pancreatic adenocarcinoma. PLoS ONE. 2007; 2:e1155. [PubMed: 17982507]

110. Nawroth R, et al. Extracellular sulfatases, elements of the Wnt signaling pathway, positively regulate growth and tumorigenicity of human pancreatic cancer cells. PLoS ONE. 2007; 2:e392. [PubMed: 17460759]

111. Romero D, Iglesias M, Vary CP, Quintanilla M. Functional blockade of Smad4 leads to a decrease in beta-catenin levels and signaling activity in human pancreatic carcinoma cells. Carcinogenesis. 2008; 29:1070-1076. [PubMed: 18310088]

112. Wang Z, et al. Blockade of SDF-1/CXCR4 signalling inhibits pancreatic cancer progression in vitro via inactivation of canonical Wnt pathway. Br. J. Cancer. 2008; 99:1695-1703. [PubMed: 19002187]

113. Hermann PC, et al. Distinct populations of cancer stem cells determine tumor growth and metastatic activity in human pancreatic cancer. Cell Stem Cell. 2007; 1:313-323. [PubMed: 18371365]

114. Hiyama E, et al. Telomerase activity is detected in pancreatic cancer but not in benign tumors. Cancer Res. 1997; 57:326-331. [PubMed: 9000577]

115. Bernhardt SL, et al. Telomerase peptide vaccination of patients with non-resectable pancreatic cancer: a dose escalating phase I/II study. Br. J. Cancer. 2006; 95:1474-1482. [PubMed: 17060934]

116. Choudhury, A., et al. Treatment of advanced pancreatic cancer patients with a telomerase-peptide vaccine together with gemcitabine: a phase II clinical study in AACR Meeting Abstracts 2007; Philadelphia: The American Association for Cancer Research; 2007. p. 1863

117. Calin GA, Croce CM. MicroRNA signatures in human cancers. Nat. Rev. Cancer. 2006; 6:857866. [PubMed: 17060945]

118. Tong AW, Nemunaitis J. Modulation of miRNA activity in human cancer: a new paradigm for cancer gene therapy? Cancer Gene Ther. 2008; 15:341-355. [PubMed: 18369380]

119. Lee EJ, et al. Expression profiling identifies microRNA signature in pancreatic cancer. Int. J. Cancer. 2007; 120:1046-1054. [PubMed: 17149698]

120. Lee CJ, Dosch J, Simeone DM. Pancreatic cancer stem cells. J. Clin. Oncol. 2008; 26:2806-2812. [PubMed: 18539958]

121. Olive KP, Tuveson DA. The use of targeted mouse models for preclinical testing of novel cancer therapeutics. Clin. Cancer Res. 2006; 12:5277-5287. [PubMed: 17000660]

122. Lev-Ari S, et al. Curcumin synergistically potentiates the growth inhibitory and pro-apoptotic effects of celecoxib in pancreatic adenocarcinoma cells. Biomed. Pharmacother. 2005; 59(Suppl. 2):S276-280. [PubMed: 16507392]

123. Kunnumakkara AB, et al. Curcumin potentiates antitumor activity of gemcitabine in an orthotopic model of pancreatic cancer through suppression of proliferation, angiogenesis, and inhibition of nuclear factor- $\mathrm{kB}-$ regulated gene products. Cancer Res. 2007; 67:3853-3861. [PubMed: 17440100]

124. El-Rayes BF, Ali S, Sarkar FH, Philip PA. Cyclooxygenase-2-dependent and -independent effects of celecoxib in pancreatic cancer cell lines. Mol. Cancer Ther. 2004; 3:1421-1426. [PubMed: 15542781] 


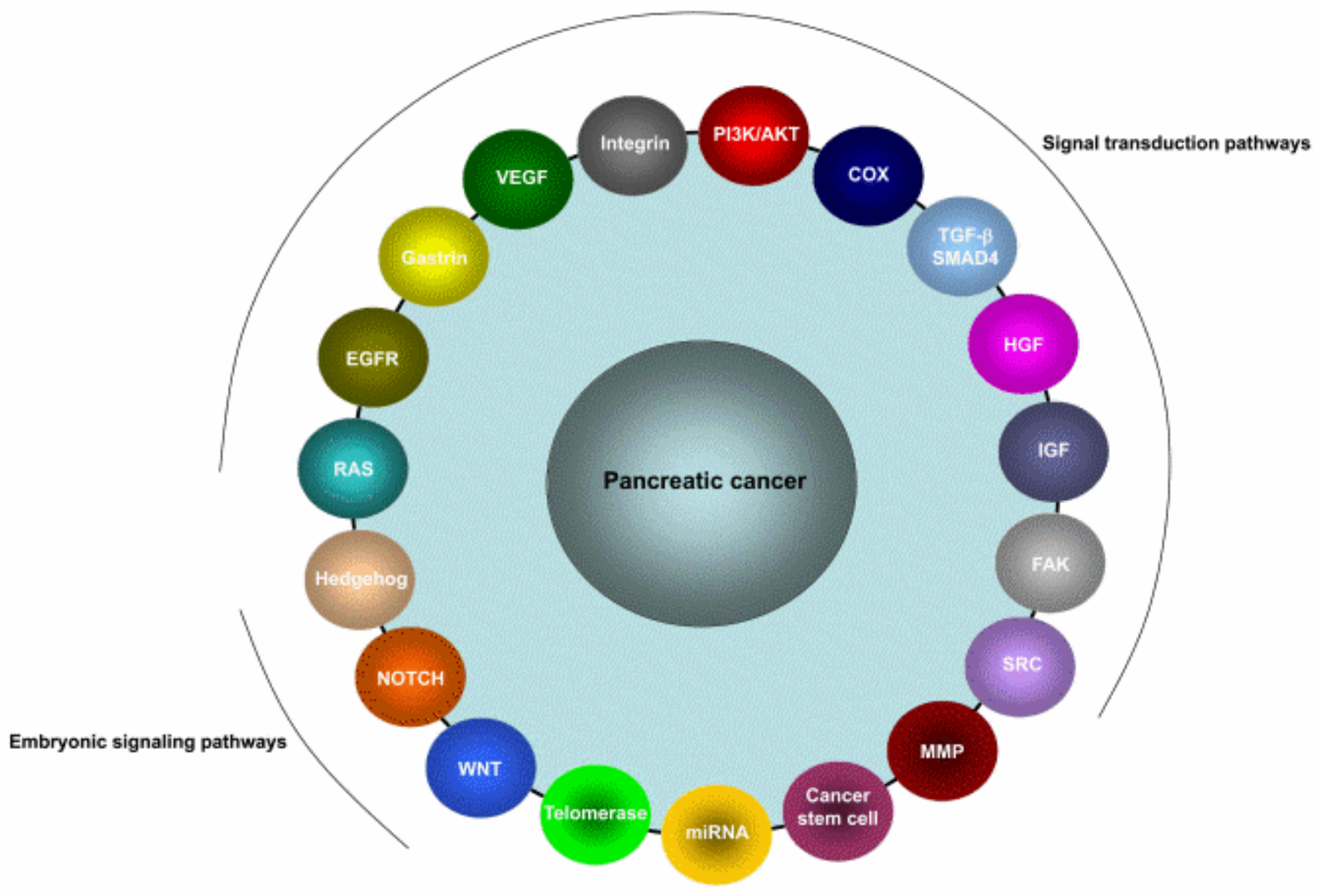

Figure 1.

The complex and overlapping pathways and processes involved in pancreatic carcinogenesis. Entities involved in these signal transduction pathways have diverse roles in the promotion of tumor growth, resistance to apoptosis, invasion, metastasis and angiogenesis. Reactivation of physiological, embryonic development pathways is also commonly observed in pancreatic cancer. MMPs are important for tumor invasion and neovascularization. Telomerase is involved in the maintenance of telomeres and is activated in the majority of pancreatic cancers. The miRNAs regulate gene expression posttranscriptionally and can be either oncogenic or tumor-suppressive. Cancer stem cells have been implicated in tumor progression, resistance to chemotherapy and radiotherapy and in disease relapse. Abbreviations: miRNAs, microRNAs; MMP, matrix metalloproteinase. 
a

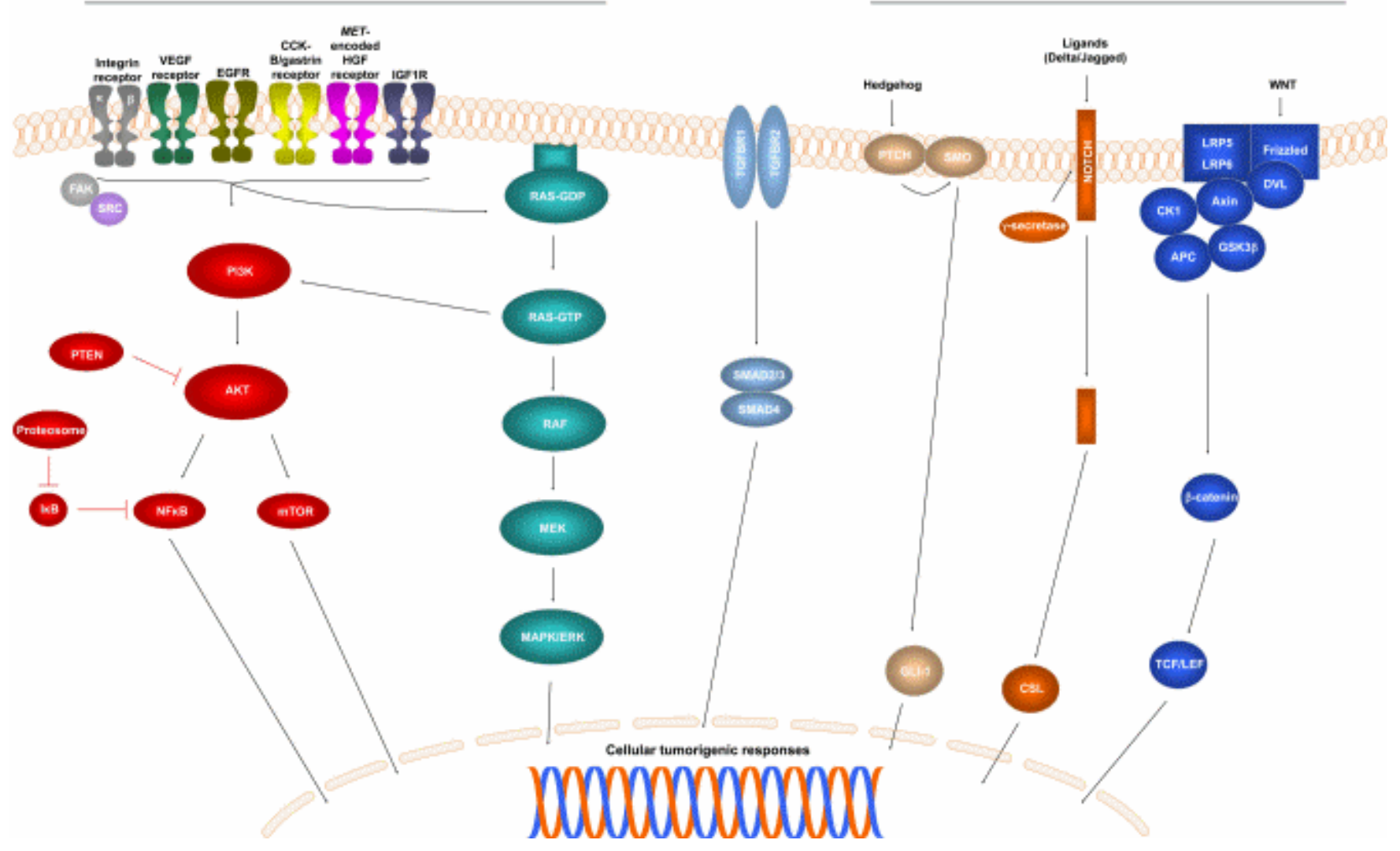

Figure 2.

A simplified representation of oncogenic signaling cascades in pancreatic cancer. a I Binding of ligands to receptors for integrins, VEGF, EGFR, CCK-B/gastrin, HGF and IGF-I activates signaling cascades including the PI3K-Akt and Ras pathways, which affect downstream targets such as NFkB, mTOR and MAPK. FADK binds to integrin receptors and Src to growth factor receptors. FADK-Src interaction increases the activity of FADK. PTEN has the opposite effect to PI3K and inhibits the Akt pathway. Proteasomes degrade I $\kappa$ B, which normally inhibits NFkB. $b$ I Binding of TGF- $\beta$ forms a complex with TGFBR1 and TGFBR2, which leads to phosphorylation of SMAD2 and SMAD3. These proteins form a complex with SMAD4, which migrates to the nucleus to activate gene transcription. $\mathrm{c}$ I The embryonic signaling pathways. Binding of hedgehog proteins to PTC1 releases inhibition of SMO, which leads to activation of downstream targets such as GLI 1. Activation of Notch by its ligands Delta and Jagged leads to its proteolytic cleavage by $\gamma$ secretase, and releases the cytoplasmic domain which translocates to the nucleus and binds to transcription factors such as CSL. $\beta$-catenin is normally destined for proteasomal degradation. In the canonical Wnt- $\beta$-catenin pathway, binding of Wnt proteins stabilizes $\beta$ catenin and induces its translocation to the nucleus. $\beta$-catenin forms a complex with the TCF-LEF transcription factors to initiate gene expression. Abbreviation: CD, cytoplasmic domain. 
Table 1

Important therapeutic targets in pancreatic cancer

\begin{tabular}{|l|l|}
\hline Target & $\begin{array}{l}\text { Frequency of mutation or expression } \\
\text { in pancreatic cancer }(\%)\end{array}$ \\
\hline Cholecystokinin-B and gastrin receptor32 & 95 \\
\hline KRAS 5 & 95 \\
\hline Telomerase114 & 95 \\
\hline Vascular endothelial growth factor37 & 93 \\
\hline Gastrin precursors and gastrin32 & $23-91$ \\
\hline Cyclo-oxygenase-267 & 90 \\
\hline Hepatocyte growth factor receptor80 & 78 \\
\hline Notch 3106, 107 & 70 \\
\hline SHH97 & 70 \\
\hline Src85 & 70 \\
\hline Epidermal growth factor receptor20 & 69 \\
\hline$\beta$-catenin108 & 65 \\
\hline Insulin-like growth factor-I receptor85 & 64 \\
\hline Activated Akt49 & 59 \\
\hline$S M A D 475$ & 50 \\
\hline Focal adhesion kinase91 & 48 \\
\hline$A K T 248$ & 20 \\
\hline$T G F B R 2$ (transforming growth factor- $\beta$ receptor II)75 & 4 \\
\hline$T G F B R 1$ (transforming growth factor - $\beta$ receptor I)75 & 1 \\
\hline
\end{tabular}




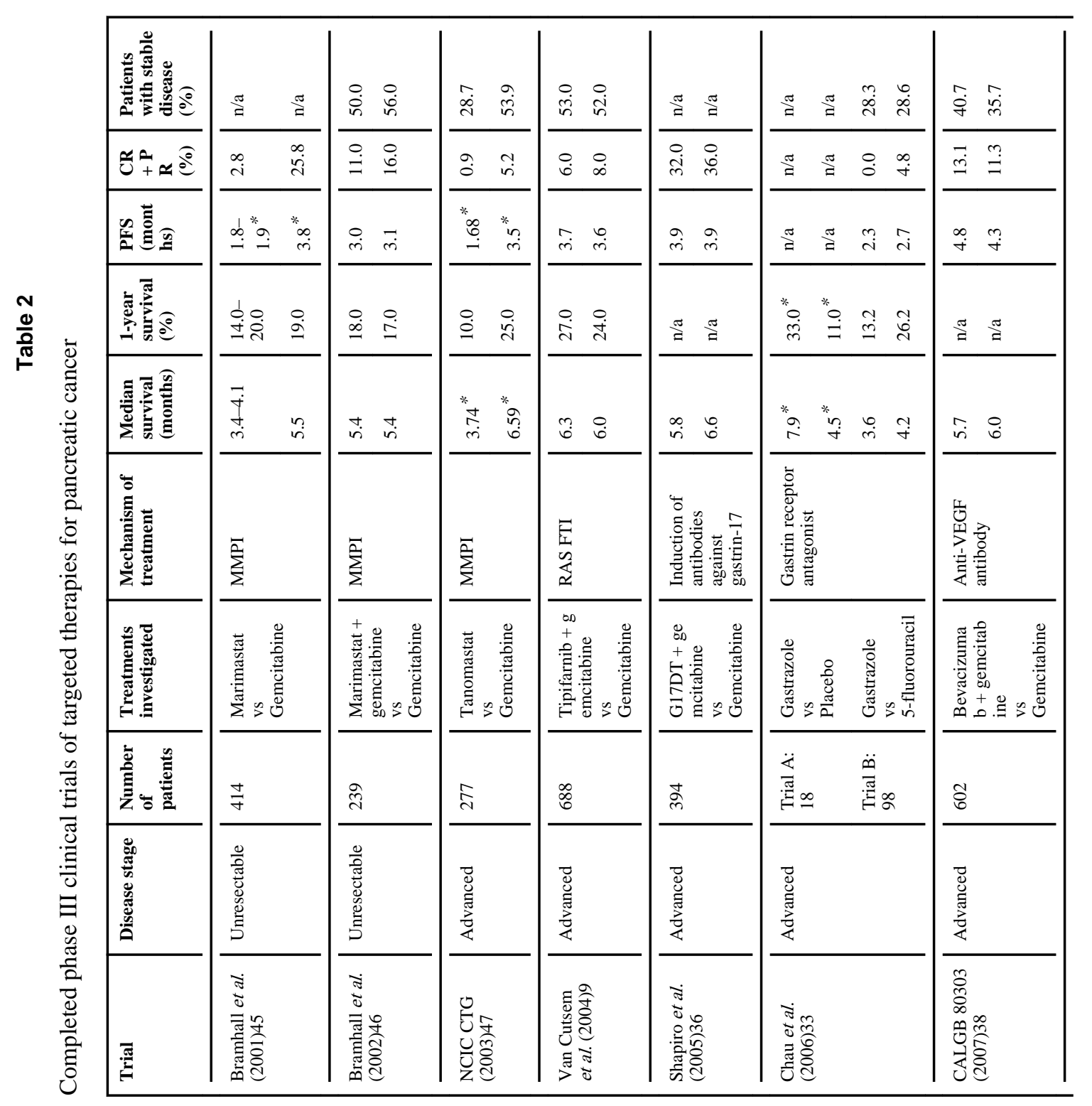

Nat Rev Gastroenterol Hepatol. Author manuscript; available in PMC 2010 June 08. 


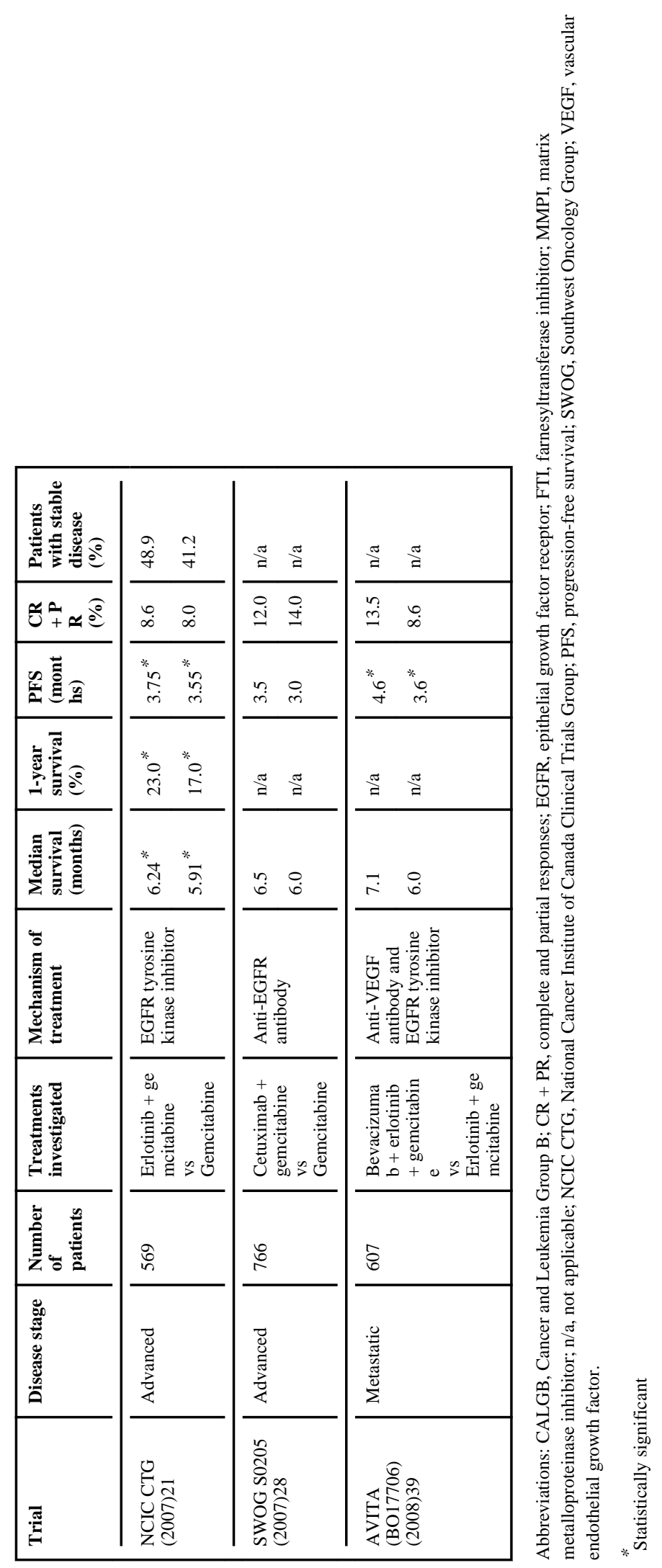

Nat Rev Gastroenterol Hepatol. Author manuscript; available in PMC 2010 June 08. 
Table 3

Ongoing phase III clinical trials of targeted therapies for pancreatic cancer

\begin{tabular}{|c|l|l|}
\hline Treatment & Target & Disease stage \\
\hline $\begin{array}{c}\text { Erlotinib, capecitabine and } \\
\text { gemcitabine }\end{array}$ & EGFR & $\begin{array}{l}\text { Locally advanced or } \\
\text { metastatic }\end{array}$ \\
\hline $\begin{array}{c}\text { Curcumin, celecoxib and } \\
\text { gemcitabine }\end{array}$ & NFKB and COX2 & $\begin{array}{c}\text { Locally advanced or } \\
\text { metastatic }\end{array}$ \\
\hline Axitinib and gemcitabine & $\begin{array}{c}\text { VEGF receptor and other } \\
\text { tyrosine kinases }\end{array}$ & $\begin{array}{l}\text { Locally advanced or } \\
\text { metastatic }\end{array}$ \\
\hline Sorafenib and gemcitabine & $\begin{array}{c}\text { VEGF receptor and other } \\
\text { tyrosine kinases }\end{array}$ & $\begin{array}{c}\text { Locally advanced or } \\
\text { metastatic }\end{array}$ \\
\hline $\begin{array}{c}\text { GV1001, capecitabine and } \\
\text { gemcitabine }\end{array}$ & Telomerase & $\begin{array}{c}\text { Locally advanced or } \\
\text { metastatic }\end{array}$ \\
\hline Aflibercept and gemcitabine & VEGF & Metastatic \\
\hline
\end{tabular}

